\title{
JOSÉ DE MENDOZA, AUTOR DE LAS ESCULTURAS DE LA PUERTA MAYOR Y COLATERALES DE LA CATEDRAL DE JEREZ DE LA FRONTERA $(1737-1741) *$
}

\author{
POR \\ ESPERANZA DE LOS RÍOS MARTÍNEZ \\ Facultad de Bellas Artes de Sevilla
}

\begin{abstract}
The sculpture work of the Cathedral's principal frontispiece of Jerez de la Frontera had remained anonymous until the present. With this article, we are going to introduce the author, Jose de Mendoza, belonging to an important family of sculptors in this town.
\end{abstract}

El templo de la Iglesia Colegial, hoy Catedral, de Jerez de la Frontera ocupa el sitio de la que fue, originariamente, la mezquita mayor de la ciudad en época almohade. En 1264, tras la reconquista y repartimiento por Parroquias de Alfonso X, quedó como Iglesia Mayor de la ciudad y consagrada al Salvador, aunque no es posible saber con certeza si se reutilizó la mencionada mezquita o si se construyó un templo nuevo ${ }^{1}$. Conocemos diversas descripciones del templo primitivo y de sus capillas, así como el dibujo que nos ha llegado en la vista de la ciudad realizada por Anton Van Der Wyngaerde en $1567^{2}$.

El suelo húmedo y con filtraciones sobre el que estaba edificada propició que desde el siglo XVI se encontrase en tan pésimas condiciones que desde entonces el Cabildo Colegial

Nuestro mayor agradecimiento al Doctor Don Domingo Gil Baro, Director del Archivo Diocesano de Jerez de la Frontera por haber tenido la deferencia de ofrecernos los documentos que nos han permitido la elaboración del presente trabajo.

1 Francisco Mesa Ginete: Historia Sagrada y Política de la Ciudad de Jerez de la Frontera. Jerez, 1888. Hipólito Sancho de Sopranis: Introducción al estudio de la Arquitectura en Jerez, en: «Guión», Jerez, 1935. José Luis Repetto Betes: La obra del Templo de la Colegial de Jerez de la Frontera. Cádiz: Instituto de Estudios Gaditanos, 1978.

2 Mesa Ginete, op. cit., T. II. Ciudades del Siglo de Oro: Las vistas españolas de Antón Van Der Wyngaerde. Richard L. Kagan (dir.), Madrid, 1986; pp. 318-319. A través de estos datos sabemos que se trataba de un templo de tres naves y cubierta de madera, similar a las Parroquias de San Lucas y San Dionisio y, como éstas, con diversas capillas añadidas en diferentes épocas. 
intentase la construcción de un nuevo edificio ${ }^{3}$, lo cual no pudo llevarse a cabo hasta los últimos años del siglo XVII.

El 7 de diciembre de 1964 cuando se cantaban los maitines de la Concepción, con la iglesia llena de fieles, se derrumbó parte del techo en medio del terror general ${ }^{4}$.

Diego Moreno Meléndez, Maestro Mayor de la Ciudad desde 1663, acudió a reconocer los daños acompañado de los alarifes Rodrigo del Pozo y Martín Guerra y del carpintero Manuel Tavares; los tres coincidieron en que la magnitud de la ruina imposibilitaba seguir usando el edificio y, en consecuencia, se hacía imprescindible levantar un nuevo templo.

El edificio se sacó de cimientos en 1695 y aunque no se ha podido documentar con certeza al autor de sus trazas, atribuimos a Diego Moreno Meléndez esta responsabilidad.

En 1700 murió dicho maestro; al poco tiempo se declaraba la Guerra de Sucesión a la vez que se terminaron los fondos del Cabildo Colegial, ocasionando la parada de las obras desde ese año hasta 1715.

En Septiembre de 1715 el Cardenal de la Archidiócesis Hispalense, Fray Manuel Arias y Porres, daba a conocer que la obra se proseguiría a sus expensas hasta su terminación; cuando en 1717 le sobrevino la muerte legó la totalidad de sus bienes para que se cumpliese esta finalidad ${ }^{5}$.

Al frente de la obra puso al Maestro Mayor del Arzobispado, Diego Antonio Díaz, bajo cuya dirección se recomenzaron los trabajos. Las dificultades para seguirlos de cerca indujeron a Diego Antonio a nombrar como delegado a su propio hermano, Ignacio Díaz de los Reyes, quien desde 1716 hacía constantes viajes desde Sevilla, instalándose definitivamente en Jerez en 1718. Hasta 1741 las obras siguieron bajo su dirección, pero en 1747 sufrían una nueva parada; en 1748 Ignacio Díaz murió en la miseria ${ }^{6}$.

Así pues, fue bajo la dirección de Ignacio Díaz de los Reyes cuando se realizaron las esculturas objeto de este artículo. Según Repetto, desde 1725 ya se encontraba esculpido sobre la portada principal el escudo real, por ser fundación regia y estar construida, en parte, con los fondos procedentes de los arbitrios reales.

En una inspección ordenada por el Corregidor de la Ciudad, fechada en 26 de agosto de 1744, Ignacio Díaz de los Reyes informaba de que en Junio de 1739 en el interior del templo se hallaban a punto de poner el cornisamiento de las naves y las capillas, así como los barandales y la media naranja de la capilla mayor. Aunque mencionase el dinero necesario para realizar en el exterior las torres, apreciando su costo en setenta y siete mil reales y el de los reductos y gradas, calculados en ocho mil, no se tasaban los trabajos de escultura que durante ese año se estaban realizando ${ }^{7}$, pues en 1737 está documentado el comienzo de los trabajos de talla en la puerta principal del templo a cargo de José de Mendoza.

3 Celestino López Martínez: Desde Jerónimo Hernández hasta Martínez Montañés. Sevilla, 1928; p. 150. Repetto Betes, op. cit., p. 49. Durante el siglo XVI se inició un nuevo edificio, trazado en parte por Hernán Ruiz «El Joven», a espaldas del que estaba en uso y que alcanzó la altura de los entablamentos. En 1621 fue detenida la obra por falta de fondos, se desmontó lo construido, pilares, arcos y entablamentos, para adosarlo a la ruinosa iglesia y reforzarla. (Esperanza de los Ríos Martínez: Hernán Ruiz II y la reforma renacentista frustrada de la Iglesia Colegial de Jerez de la Frontera, en: «Atrio», n.․ 5; Sevilla, 1993; pp. 15-24: Antón Martín Calafete y Diego Moreno Meléndez en la arquitectura jerezana del siglo XVII. Sevilla: Consejería de Cultura. Dirección General de Bienes Culturales. [En prensa]).

${ }^{4}$ Repetto Betes, op. cit., p. 64; Ríos Martínez, Antón Martín Calafete y Diego Moreno Meléndez..., cap. IV.

5 Repetto Betes, op. cit., p. 75.

6 Repetto Betes, op. cit., pp. 184-185.

7 Repetto Betes, op. cit., p. 311. 
José era hijo del escultor jerezano Francisco Camacho Mendoza, autor de obras de gran interés conservadas en Jerez y en diversas ciudades de la Provincia de Cádiz ${ }^{8}$. También tuvo relaciones profesionales con la actual capital provincial, donde se documenta su intervención en la iglesia del Convento del Carmen; para este templo restauró una imagen de la Virgen del Carmen aunque cabe intuir que no fue éste su único trabajo en dicha ciudad ${ }^{9}$.

José de Mendoza, siguiendo los usos de filiación de la época, utilizó exclusivamente los apellidos paternos si bien trocando su orden y usando alternativamente uno u otro, como también hizo su padre. Así pues, los escasos documentos que acerca de él nos han llegado le nombran en una ocasión Camacho, en otra Camacho y Mendoza y, en el relativo a su producción en Jerez, aparece como Mendoza. Debió aprender el oficio con su padre, aunque posteriormente se trasladase a Cádiz donde su actividad, hasta el momento, sólo estaba registrada tallando capiteles para la Catedral Nueva, donde se le localiza desde 1739 a 1748 trabajando como tallista: «labrante de piedra dura», a las órdenes de Cayetano de Acosta ${ }^{10}$.

En 1739 los pagos que se efectuaban en la Catedral gaditana se referían a la talla de capiteles para las capillas que se cerraron en aquel año. En esta labor colaboraban con Acosta los escultores Carlos de Vargas y Diego Tabares (sic) quien tal vez también era jerezano e hijo del anteriormente citado José Tavares, maestro mayor de carpintería de Jerez. El escultor que nos interesa figura nominado en este año como José Camacho.

A partir de 1741 hasta 1744 debieron hacerse trabajos de tipo más constructivo que decorativo aunque los tallistas siguieron en sus puestos pues continuaban cobrando semanalmente y la fábrica proseguía adquiriendo materiales para dichas labores. Por otra parte, Acosta no dejó de residir en Cádiz a lo largo de esos tres años.

Desde 1744 la obra se hallaba a nivel de frisos casi en su totalidad, pues desde entonces son continuos los pagos por capiteles y pilastras a diversos tallistas, entre ellos nuestro escultor, en este caso mencionado como José Camacho y Mendoza ${ }^{11}$, quien no parece haber tenido ningún problema en realizar su trabajo de escultor de forma simultánea en la Catedral y Colegiata que se estaban levantando al mismo tiempo en Cádiz y Jerez.

En el aspecto profesional la última noticia conocida acerca de José es que en 1752 se comprometía a ejecutar cuatro arbotantes para los retablos colaterales del Sagrario de la Catedral Hispalense, trabajo que no llegó a realizar ${ }^{12}$. Ésta que centra nuestro artículo es, por lo

8 Entre éstas se encuentra el retablo de Animas de la Parroquia de San Lucas, en Jerez, obra documentada por Lorenzo Alonso de la Sierra Fernández y Francisco Herrera García: Aproximación a la escultura jerezana del siglo XVIII: Francisco

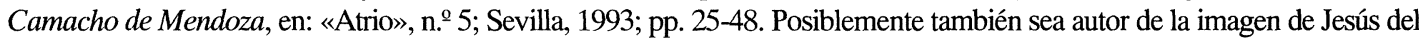
Prendimiento, de la Parroquia jerezana de Santiago, como consideran José Miguel Sánchez Peña en su artículo Nuevas aportaciones a la escultura andaluza del XVIII. En: Boletín del Museo de Cádiz; n. ${ }^{\circ}$ IV; Abril 1987, pp. 129-134 y Fernando Arora Vicenti: Aportaciones al retablo del siglo XVIII en la Baja Andalucía: El modelo jerezano, en: «Laboratorio de Arte», (En Prensa). Sánchez Peña, entre sus obras documentadas en otras ciudades cita las tallas de Santo Domingo de Guzmán, de la Parroquia del mismo nombre de Sanlúcar de Barrameda y el San José con el Niño de la Parroquia de la O en Rota.

Era una talla de vestir que presidía el retablo mayor, firmada en su espalda por Jacinto Pimentel y datada en 1638, para la cual Camacho realizó unas manos nuevas, tal vez por haberse incendiado las originales; además le puso ojos de cristal (Carmen Aranda Linares, Enrique Hormigo Sánchez, José Miguel Sánchez Peña: Scultura lignea genovese a Cadice nel Settecento. Genova: Associacione Amici della Biblioteca Franzoniana, 1993; p. 42).

${ }_{10}$ Este escultor lisboeta ocupó el puesto de primer tallista durante al menos doce años; comenzó a trabajar en 1730 sustituyendo a su antecesor en el cargo, Carlos de Vargas y permaneciendo al frente de su puesto hasta 1751, año en el que ya había regresado a Sevilla para colaborar en la decoración de la Fábrica de Tabacos (Hoy Rectorado). (Alfonso Pleguezuelo Hernández: Aportaciones a la biografia y obra de Cayetano de Acosta: la fase gaditana, en: «Boletín del Seminario de Arte y Arqueología»; Universidad de Valladolid, T. LIV, 1988; pp. 483-501).

${ }^{11}$ Idem, p. 491 y p. 493.

12 Francisco Cuéllar Contreras: Los retablos colaterales de la iglesia del Sagrario de Sevilla, en: «Atrio», n. ${ }^{2}$; Sevilla, 1992; pp. 95-110. 
tanto, no sólo su primera obra documentada en Jerez, sino también la primera realizada con carácter personal e individualizado que conocemos. No sabemos con certeza dónde residió durante estos años hasta que, al parecer, se avecindó en Jerez durante un tiempo, pues el 24 de Diciembre de 1747 recibió en traspaso una casa situada en la collación de Santiago, en la calle de Piernas (actualmente Guadalete), donde residía Francisco Camacho con el taller y el resto de la familia en una vivienda de su propiedad.

Tras la muerte del padre, ocurrida el 19 de diciembre de 1757, su hermano Bartolomé Diego recibió el 8 de febrero de 1758 el traspaso de la mitad de una casa que lindaba por un lado con la que Francisco había dejado en herencia y por otro con la que José habitaba. Tras negociar una medianía que las separaba, la familia se encontró residiendo en casas contiguas formando así un taller de grandes dimensiones ${ }^{13}$.

En cuanto a nuestro escultor no tenemos más noticias suyas hasta 1760, año en el cual su madre, Francisca Ramos, daba a su hijo Bartolomé Diego un poder para testar; en este documento se precisa que José se encontraba ausente de España por haber marchado a Indias; no sabemos nada de su actividad en América, ni tampoco si regresó a su país ${ }^{14}$.

Bartolomé Diego pudo residir durante un período de su actividad profesional en Cádiz, simultaneando su trabajo en las dos ciudades, de forma similar a su hermano José ${ }^{15}$, en unas fechas compatibles con su actividad profesional en Jerez documentada en años posteriores, donde colaboró con su padre en diversos trabajos como dorador y estofador. La última noticia que hay de él es de 1763, año en que se comprometía notarialmente a devolver un préstamo ${ }^{16}$.

En cuanto a la obra que centra nuestro trabajo, se encuentran documentadas las escultoras de la puerta mayor, dedicada a la Transfiguración y los relieves y esculturas de las dos menores que la flanquean, representando respectivamente el Nacimiento y la Epifanía pero acerca de las cuales no constan las fechas de ejecución ni los pagos. Estas tres escenas, junto con las de las portadas del transepto, dedicadas a la Visitación y Encarnación, forman un programa iconográfico completo, reforzado por la semejanza en la técnica de la talla, que no permiten dudas acerca de la responsabilidad de Mendoza y su taller en todas ellas.

El conjunto de esculturas que componen la escena principal gira en torno al tema central de la advocación que da nombre al templo: El Divino Salvador, representado en la escena de su Transfiguración en el Monte Tabor.

Por el momento no nos ha llegado la escritura notarial del concierto, por lo cual desconocemos las condiciones que se establecieron para su ejecución y el autor de su programa iconográfico.

13 Lorenzo Alonso y Francisco Herrera: Aproximación a la escultura jerezana del siglo XVIII...; pp. 25-48.

14 Aroca Vicenti, Aportaciones al retablo del siglo XVIII... nota 26.

15 En Cádiz, en el Archivo Parroquial de Santa Cruz, consta el matrimonio de un Bartolomé Camacho con Ignacia Heredia, casados el 13 de julio de 1741. En el mismo Archivo consta el nacimiento de cuatro hijos de esta pareja; el primero nació en 1742; bautizado con el nombre de Félix, falleció en 1753; Manuel nació en 1744 y José en 1748; el último parece ser Antonio Pedro Domingo Tomás, nacido en 20 de Diciembre de 1754 y bautizado el 22 del mismo mes y año (Cádiz. Archivo Parroquial de Santa Cruz. Libro de Matrimonios, n.o 26 , folio 167. Libro de Bautizos, n.. 51, folio 160; Libro de Defunciones, s/n. 1753, folio 279 v. ‥ Libro de Bautizos, n. ${ }^{\circ}$ 52, folio 206. Libro de Bautizos, n..$^{9}$ 4, folio 31. Libro de Bautizos, n. ${ }^{\circ}$ 57, folio 148 v. ‥ (Agradecemos al investigador Don José Miguel Sánchez Peña el suministro de estos datos y su desinteresada colaboración en este trabajo).

16 Intervino en el retablo mayor que aquél hizo en 1750 para la parroquia de Santiago (desaparecido durante la fiebre purista decimonónica); en 1759 aún cobró 23.760 reales de resto por su trabajo. Más tarde intervino en varios retablos del desaparecido hospital de San Juan de Dios en Jerez y a continuación doró y estofó las imágenes del retablo mayor de la iglesia de esta misma orden en el Puerto de Santa María (L. Alonso de la Sierra y Fco. Herrera, op. cit., p. 27). 
El Libro de Cuentas de la Obra del Nuevo Templo, 1738-1741 (Apéndice Documental) refleja la continuidad con que se realizaron las esculturas y la sistemática libranza de los pagos. El contador de la obra anota «Tengo ajustado con Joseph de Mendoza que ha de hacer las efigies para la Puerta Mayor a 15 Pesos de a 8 de Pta. cada una y para las dos puertas de los lados los dos Misterios de Nacimiento y Epifanía a 45 Pesos cada una». En 1737 debieron iniciarse los trabajos pues los pagos se empezaron a librar «a cuenta» desde el 19 de marzo del 1737, en que se le entregaron 5 pesos a José de Mendoza.

Los pagos sucesivos, en esta primera fase, son muy continuos; muchos de ellos se hacen en pesos de plata, moneda habitual entre los artífices gaditanos que trabajaban en Jerez, aunque también se use, en este caso, el real de vellón. El siguiente se hizo el 30 del mismo mes, prosiguiendo éstos en 17 y 27 de abril; 11, 20 y 25 de mayo; 8,17 y 27 de junio; 12,22 y 29 de julio; 3 y 20 de agosto; los más continuos fueron los de Septiembre, datados en 5, 9, 12; el día 13 se declaraba que estaban liquidadas nueve esculturas, «hasta la imagen de San Rafael», que es una de las que forman el remate de la portada. Se continuaron los plazos durante los días 17, 25 y 30 del mismo mes.

El 12 de Octubre con 5 pesos se abonaba la imagen de San Gabriel y el 7 de Noviembre con la entrega de 10 tablas a precio de 10 reales y medio cada una, por un total de 75 reales, se daba por remunerada «una efigie de Ángel», quizás la de San Miguel que centra el remate del conjunto.

En el término de pocos días, el 23 de noviembre, cobró 75 reales de vellón por la escultura de San Pedro, que formaba parte de la escena central de la portada, el denominado «Misterio de Tabor». Casi inmediatamente, el 2 de Diciembre, Mendoza entregaba otra escultura cuya iconografía no se especifica, por la cual se le dieron 135 reales. Los pagos proseguían en Enero de 1738; el 15 de Febrero se anotaba que tenía realizados hasta ese día 15 flameros y 2 tulipanes, a cuatro reales y medio cada uno. Está claro que en el concierto de la obra se debía especificar que el escultor se ocuparía también de los elementos decorativos de los remates. El 11 de Marzo se le ajustó al escultor la cuenta por el total de lo que había realizado; se le dieron 166 reales con lo cual quedaban saldadas diecisiete esculturas terminadas, además de dieciocho flameros a 4 reales cada uno y cuatro tulipanes a 15 reales la unidad; la cuenta total fue de 3.957 reales.

Sin embargo, la portada aún tenía que ser completada y José prosiguió su cometido, siendo satisfecho puntualmente a lo largo de los meses de Abril, Mayo, Julio y Agosto; en los días 14 y 15 de este último se le entregaron 8 pesos, con lo cual se completaba la retribución de otras dos efigies que había concluido así como otros cuatro tulipanes.

Se siguen anotando los libramientos a lo largo de Agosto y hasta el 13 de Septiembre de 1738 , fecha en que hay una interrupción en las cancelaciones pues según se desprende por las cuentas no se continuaron hasta casi un año después, el 4 de Mayo de 1739, cuando el escultor había realizado otras tres esculturas con lo cual se completaba el número de veintidós imágenes que componen la puerta mayor, todas ellas de piedra de Martelilla, cuyo precio total fue de 4.920 reales. El 16 de Julio del mismo año concluyó la talla de unas figuras de ángeles por las cuales cobró 518 reales.

Recordamos que en este mismo año de 1739 es cuando Mendoza aparece en la nómina de tallistas en la Catedral de Cádiz; es posible que esta obligación le hiciese espaciar las entregas para la Colegiata de Jerez.

A lo largo de 1740 carecemos de noticias, tal vez porque estuviese más entregado a sus obligaciones en Cádiz, teniendo en cuenta lo avanzado de su trabajo para la Colegial. Sin embargo no cesó por completo su actividad en Jerez, pues el 20 de Agosto de 1741 se le 
ajustaron cuentas por los florones de los remates, a un precio cada uno de ellos de 4 reales y medio; el 16 de Septiembre recibió 75 reales por 30 remates y 12 pesos por los ángeles que coronan las cubiertas de los cilindros donde se contienen las escaleras de caracol que encuadran la portada.

Es interesante comprobar cómo el conjunto escultórico nos ha llegado en el color natural de la piedra, cuando en su origen estuvo coloreado, a modo de espectacular retablo. Si se observan con atención algunas partes aún se podrán apreciar restos de color rojo, azul y verde. El encargado de esta policromía fue, como se dijo más arriba, el hermano del escultor, Bartolomé Diego de Mendoza, nominado escuetamente en el Libro de Cuentas como Diego de Mendoza.

No sabemos con exactitud cuándo comenzó a trabajar aunque lo normal es que fuese policromando a medida que se terminaban las imágenes. En el verano de 1739 se le hicieron cuatro pagos, en 12 de Junio, y en 9, 18 y 27 de Julio, por un total de 4.085 reales. En el Libro, muy escueto, no se especifican los colores empleados, aunque al parecer no se usó el pan de oro.

Cada una de estas imágenes llevaba, además, su atributo iconográfico realizado en metal. De este trabajo se encargó el latonero Vicente Sabariego, quien empezó a cobrar por su trabajo en fecha del 15 de Abril de 1735. Ese día cobró 147 reales por 24 libras de metal empleadas en realizar dos diademas, una espada, dos llaves y cuatro garras. El 18 de mayo cobró 40 reales por una corona y un sol para la Sibila: el 22 de Junio llevó la diadema para la figura central, El Salvador, que importó cuatro pesos y 24 de Agosto, el bastón de San Miguel.

No hay más pagos hasta el 2 de Junio de 1738 en que entregaba la espada para San Elías, continuando el 10 de Septiembre en que cobró la cruz que lleva en el orbe el Padre Eterno y su diadema, así como otra cruz para un ángel-niño que le acompaña, que importó dos pesos, con lo cual concluyen las cuentas de esta obra.

La puerta principal está situada a los piez de la iglesia, a eje con su nave principal y se distribuye en dos cuerpos.

El primer cuerpo queda flanqueado por pilastras cajeadas de fuste tallado con motivos vegetales de estilizada planitud. Dos columnas de orden compuesto dan paso al vano central, que es adintelado y sobre el cual una hornacina con columnas salomónicas, alberga una imagen de la Inmaculada. Este vano queda encastrado en un pequeño vestíbulo abierto en medio punto, siguiendo una tradición arquitectónica de la ciudad heredada del siglo XVII. El remate lo compone un frontón semicircular abierto sobre el cual se han situado sendas figuras alegóricas; está centrado por el escudo real sostenido por ángeles-niños.

El segundo cuerpo es un espacio largo y estrecho que guarda relativa semejanza con las torres-fachada de otras Parroquias de la ciudad.

Los cilindros que albergan las escaleras o «caracoles» para subir a las bóvedas flanquean la escena de la Transfiguración. El conjunto queda rematado por otro frontón curvo partido que sirve de marco al rompimiento de gloria que alberga al Padre Eterno. Sobre la cornisa del templo, la imagen del Arcángel San Miguel y sobre las cúpulas de los cilindros los otros dos Arcángeles crean el ilusionismo de una aparición celestial.

Las figuras que vamos a analizar nos remiten de forma inmediata a la obra de Francisco Camacho, autor documentado de obras que, a su vez, nos remiten a la produccón que José de Arce dejó en la ciudad en el siglo anterior, por lo cual podemos considerar a ambos como continuadores lejanos del estilo de dicho artista ${ }^{17}$.

17 Este retablo hubo de ser restaurado en 1715, siendo Francisco Camacho, padre del escultor que nos ocupa, quien corrió a cargo de estos trabajos (Fernando Aroca, Aportaciones al retablo del siglo XVIII...). 
El conjunto escultórico está concebido como un retablo no arquitectónico. La escena de la Transfiguración en el Monte Tabor (figs. 1 y 2) está representada tal y como se describe en los Evangelios (Mateo 17, 14-20; Marcos 9, 1-13; Lucas 9, 37-43). Cristo aparece representado sobre una nube en la cima del monte, «...con el rostro brillando como el sol y con los vestidos tan blancos como la luz». En la portada jerezana se ha empleado como elemento ilusionista la ventana mixtilínea que da luz a la nave principal, para que, centrada con la figura de Cristo, quede dispuesta a modo de aureola.

A ambos lados, sobre los soportes laterales, se representan las figuras de Elías con su espada y Moisés apoyado sobre las Tablas de la Ley, en conversación con Él; a sus pies, San Pedro en el centro y a ambos lados Santiago y San Juan, arrodillados sobre las rocas, contemplan aturdidos el milagro. Sobre Jesucrito, en un rompimiento de gloria, invisible para los Apóstoles, el Padre Eterno (fig. 3) rodeado de ángeles pronuncia las palabras que éstos sintieron salir de una nube: «Éste es mi Hijo amado en quien tengo mi complacencia; escuchadle».

Siguiendo a Louis Réau, este pasaje puede considerarse como una Cristofanía «ante mortem», aunque según el iconógrafo parece una interpolación pues, al igual que la Pesca Milagrosa debió estar originariamente entre las Apariciones de Cristo Resucitado; desde el punto de vista iconográfico este autor la clasifica como un anticipo de la Ascensión, con la cual acaba identificándose ${ }^{18}$.

En la cornisa de la portada figuran los tres Arcángeles: San Miguel (fig. 3) está situado en el centro; sobre las cúpulas que cubren los semicilindros se han distribuido imágenes de ángeles (fig. 4) que siguen muy de cerca los modelos berninescos ya usados por el escultor flamenco José de Arce en los Arcángeles del retablo mayor de la Parroquia de San Miguel ${ }^{19}$.

Bajo la figura de San Miguel, en un frontón curvo abierto sustentado por un querubín apoyado en una tarja, se encuentra la imagen del Padre Eterno, bendiciendo con la mano derecha, miestras sostiene el Orbe con la izquierda. Muy similar al de la puerta de la Encarnación, muestra una larga y revuelta cabellera con un mechón caído sobre la frente y barba-río. Recuerda en su composición a la imagen de esta misma iconografía que remata la portada de la iglesia de la Cartuja de la Defensión, realizado por Francisco de Gálvez en 1664.

La imagen de El Salvador guarda un evidente parecido con la de Jesús del Prendimiento de la parroquia de Santiago, obra atribuida a Francisco Camacho. Cristo muestra su rostro en ligero escorzo de tres cuartos; su serena belleza está próxima a la idealización clásica. Sus ojos son almendrados, con la pupila sin tallar al modo helenístico, para darle a la figura carácter de éxtasis e intemporalidad. La nariz es recta y fina; la barba bífida.

La semejanza mayor con el Prendimiento se presenta en el cabello, distribuido en grandes ondas que parten de la raya central y forman sobre el hombro derecho un movido mechón ejecutado con la misma soltura técnica de su modelo. Viste una túnica que, anudada en la cintura con un cordón, forma un triple frunce sobre el pecho, cayendo en pliegues paralelos hasta cubrirle los pies. El manto, agitado por el viento, le envuelve el hombro y el brazo izquierdo, ciñéndolo por detrás y arremolinándose bajo su brazo derecho. El tejido está trabajado a grandes trazos, ondulantes y vigorosos que remiten al Apostolado de la Cartuja de la Defensión, realizado por José de Arce entre 1636 y 1639.

18 Louis Reau: Iconografía del Arte Cristiano: Iconografía de la Biblia: Nuevo Testamento. 5 vols. Barcelona: Ediciones del Serbal, 1998; T. 1, Vol. 2, pp. 597-603.

${ }_{19}$ Para todo lo referente a este escultor: Esperanza de los Ríos: José de Arce y la escultura jerezana de su tiempo, 1636-1650. Cádiz: Diputación Provincial, 1991 y Nuevas aportaciones documentales a la vida y obra de José de Arce en Jerez de la Frontera y Cádiz, en: «Archivo Español de Arte», n. ${ }^{\circ} 268$. Consejo Superior de Investigaciones Científicas. Departamento de Historia del Arte «Diego Velázquez». Madrid, 1994, pp. 377-390. 

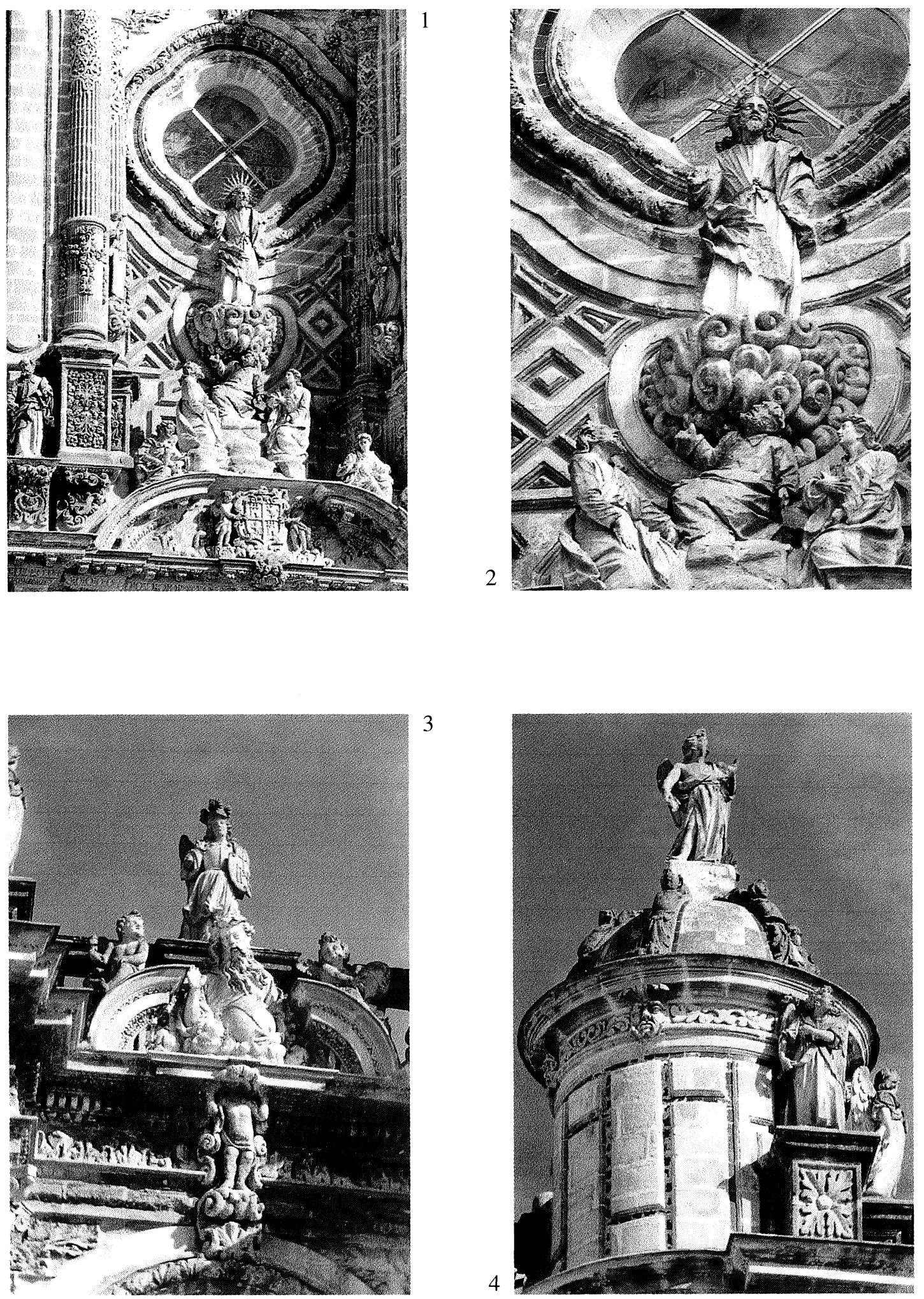

José de Mendoza. Figuras 1-2. La Transfiguración, conjunto y detalle.

Figura 3. El Padre Eterno y San Miguel.

Figura 4. Ángeles en los remates de las escaleras. Jerez de la Frontera (Cádiz). Catedral. Portada principal. 
Los tres Apóstoles guardan semejanza con el retablo de Ánimas de la Parroquia de San Lucas, obra de Francisco Camacho documentada en 1725. En dicho retablo, como intercesor de las Ánimas ante la Virgen, aparece el Evangelista titular de la Parroquia; representado con la rodilla izquierda genuflexa y la mano derecha sobre el corazón, su postura es idéntica a la del San Juan del grupo que estudiamos, si bien la talla de la túnica del Apóstol es más suelta y dúctil que en su posible modelo y su mano sobre el corazón muestra una técnica depurada; esta mano recuerda las del San Juan de la Hermandad del Desconsuelo de la Parroquia de San Mateo en esta misma ciudad, realizada en el primer tercio del siglo XVIII, si bien tanto el modelado como la actitud y la vigorosa talla encuentran su precedente en el San Bruno de La Cartuja, realizado por Arce hacia 1639.

Conforme a la iconografía tradicional su joven rostro es imberbe y presenta un perfil suave y redondeado; su expresión es abstraída y dulce; el cabello del Evangelista, recogido sobre la oreja en grandes y suaves ondas talladas a grandes mechones muestra parte de la oreja remitiéndonos, así mismo, a las imágenes del Prendimiento y de San Juan citadas, con su precedente lejano en la obra de Arce.

San Pedro está representado como un hombre calvo y maduro con barba redondeada ${ }^{20}$; el rostro, en tres cuartos, es de gran expresividad y realismo, lejos de la idelización de la figura central. También genuflexo, su actitud es de estática sorpresa, abriendo los brazos con gesto apasionado; ambas manos han desaparecido por las inclemencias del tiempo. Sus vestidos muestran un plegado anguloso muy similar al Evangelista del retablo de Ánimas mencionado. Tanto su aspecto físico como su actitud parecen inspirados en su homónimo de La Cartuja.

En cuanto a Santiago ${ }^{21}$, algo más joven, se le representa en un perfil acentuado por una barba puntiaguda, mirando hacia arriba con un gesto que remarca su agudo contorno; los cabellos peinados hacia detrás le descubren la oreja; su nariz es de rasgos semíticos y, como sus compañeros, entreabre los labios con gesto de sorpresa. Lleva túnica y manto tallados en pliegues gruesos cuyo recuerdo nos remite, una vez más, al conjunto cartujo, aunque sean más angulosos en este caso.

Sobre el frontón curvo partido que hay sobre la puerta y flanqueando la escena principal observamos dos figuras femeninas ataviadas con túnicas y mantos anudados sobre el escote; ambas llevan los cabellos ondulados y recogidos sobre las orejas que se muestran descubiertas.

Según se expresa en el documento, representan a dos Sibilas y esta misma iconografía corresponde a las figuras femeninas que con análoga distribución aparecen en las cuatro portadas menores.

En este caso concreto su disposición se corresponde con las imágenes alegóricas de la puerta exterior de la Capilla Sacramental de la Parroquia de San Miguel y que se estaban realizando en años cercanos a las que nos ocupan ${ }^{22}$ con las cuales, en nuestra opinión, guardan gran similitud estilística, tal vez por ser también obra del mismo escultor.

Las Sibilas estuvieron dotadas de poderes proféticos y según la tradición, la primera de ellas fue una hija de Zeus; Varrón citaba solamente a diez como las más importantes: la Pér-

20 L. Réau: Iconografia del Arte Cristiano: Iconografia de los Santos. T. 2, V. 1, pp. y T. 2, V. 3, pp. 43-69.

21 Ibidem., pp. 169-183.

22 Debió realizarse entre los años de 1733 y 1739, pues en éste se pagaron 1.430 reales por cinco figuras de las que integran el conjunto y, posteriomente, también fueron policromadas (Fernando Aroca Vicenti: La Capilla Sacramental de la Parroquia de San Miguel de Jerez de la Frontera, en: «San Miguel. Revista Commemorativa del V Centenario», n. .2 , Jerez, 1990; p. 20 y p. 23. 
sica, la Délfica, la Líbica, la Eritrea, la Cumana, la de Samos, la del Helesponto, la de los Cimerios, la de Frigia y la de Tíbur ${ }^{23}$. Aunque procedentes del mundo clásico, pervivieron en el Arte Cristiano por estar contrapuestas iconográficamente a los Profetas, al considerarse a éstos y a aquéllas como testimonio de la continua espera de la Redención por parte de la $\mathrm{Hu}$ manidad, transmitiendo la esperanza de su llegada. Mientras que los Profetas anticiparon efectivamente su venida, las Sibilas están ligadas a tiempos anteriores porque dicha espera no puede ser exclusiva de un pueblo sino que implica a la Humanidad entera. Las dos que nos ocupan se emparejan, en este sentido, con las figuras de Moisés y Elías que completan la escena del Tabor.

La situada a la izquierda del espectador muestra un rostro juvenil y una ligera sonrisa en los labios mientras sujeta entre sus manos un cordero; por su belleza podemos relacionarla con la Sibila Délfica.

La otra figura presenta, en contraste, un rostro macilento y grave; está sentada y sobre su rodilla izquierda sostiene un libro abierto que sujeta con la mano, atributo común de todas ellas. En los Libros Sibilinos, según la leyenda, se contenían, en un principio, las profecías sobre los destinos de Roma y se consultaban en casos de gravedad extrema ${ }^{24}$.

Por último, la figura más cercana al espectador es la Inmaculada Concepción (fig. 5), cuya imagen se realizó en memoria del Voto Inmaculadista del Cabildo. Está situada en un nicho entre columnas salomónicas, rematado por un frontón abierto; la talla es exenta, de pequeño tamaño, una vara más o menos $(80 \mathrm{~cm}$.). Se asienta sobre una peana de ángeles-niños y sobre ésta, la media luna decorada con tres cabezas de querubines. Quizás en su origen mantuviese unidas las manos, hoy desaparecidas; lleva el cabello ligeramente ondulado y pegado al cráneo, mostrando el rostro inclinado a un lado con la mirada dirigida hacia el cielo. La túnica, de forma semejante a la de El Salvador, cae en pliegues paralelos dibujando la forma de la rodilla; el manto, muy amplio, se despliega ampulosamente en los laterales, según los modelos habituales de los inicios del siglo XVIII.

Sobre el arco del vestíbulo dos ángeles-niños sostienen el escudo de la Casa Real, en memoria de la protección dispensada durante su construcción y por ser el templo una fundación real.

$\mathrm{La}$ arquitectura de las portadas menores adyacentes a la que acabamos de estudiar es mucho más simple e idéntica entre sí. Están encuadradas entre pilastras cajeadas y talladas con motivos vegetales muy planos; el entablamiento partido está rematado por jarrones sobre podios y en su centro, a modo de ático, se encuadra a la izquierda del espectador, la escena de la Epifanía y a la derecha, el Nacimiento; el remate lo conforma un frontón curvo partido sobre el que se asientan las respectivas Sibilas, cuya identidad, por haber desaparecido sus manos con los atributos correspondientes, es imposible discernir, conservando únicamente los libros como símbolo genérico.

Los dos relieves de las puertas que flanquean a la central son muy inferiores técnicamente por haber participado el taller en su elaboración, posiblemente durante los períodos en que Mendoza pudo encontrarse más ocupado cumpliendo sus obligaciones en Cádiz o en el mismo Jerez. Las tallas son notablemente más bastas que en la portada principal; las figuras se

\footnotetext{
23 Mitología. Editor Literario: Víctor Civitá; Sao Paulo. Abril, 1974, 2 Vols.; T. II, cap. 44.

24 Ibidem., La Sibila que llevaba el Sol estaría representada según la imagen de la Profecía, tal como se la describe en la Iconología de Césare Ripa, pero no sabemos cuál de ellas era su portadora, por la mencionada pérdida de las manos de casi todas y, en consecuencia, de sus posibles atributos.
} 
desenvuelven en unos espacios demasiado pequeños donde los personajes resultan desproporcionados y se adaptan al encuadre forzadamente.

En el del Nacimiento la fuente fundamental es la narración del Evangelio de San Lucas 2, 1-20; su antecedente formal más directo es el encasamiento del mismo tema en el retablo mayor de San Miguel, realizado por Arce. Ambos relieves jerezanos tienen un modelo común: el Retablo del Nacimiento del Museo de Amberes, pintado por Pedro Pablo Rubens hacia 1625, si bien éste que estudiamos aparece muy simplificado en relación a sus precedentes. En primer término, como en los citados modelos, el Niño Jesús recostado en el pesebre aparece flanqueado por la Virgen que le incorpora y por San José, representado como un hombre joven; detrás de éste, un tronco de árbol que sustenta el techado del portal, separa la Sagrada Familia de un pastor calvo que se acerca con gesto sorprendido. Completa la escena una mujer con un cesto en la cabeza; este personaje está relacionado con las matronas que aparecen en el relato de este hecho en el Evangelio Apócrifo del Pseudo-Mateo y también se la representa en el retablo antes citado ${ }^{25}$.

La Adoración de los Magos o Epifanía (Mateo 2,1-12) evidencia así mismo su parentesco con el correspondiente relieve de Arce en San Miguel. En el ángulo inferior derecho de la composición, la Virgen aparece sentada con el Niño sobre sus rodillas y con la cabeza cubierta por un velo, llevando idéntico peinado a su modelo. Detrás de ella, San José, al que enmarca un arco de medio punto idéntico a su modelo; hacemos notar que de forma similar a Arce, Mendoza representa al santo como un hombre joven, con cabello largo peinado con raya en el centro.

Ante este grupo, arrodillado, el Rey Gaspar le ofrece una naveta (desaparecida) con incienso «como a Dios»; detrás, de pie, Melchor tocado con corona real, le ofrece un cofre de oro «como a Rey» y Baltasar, llevando un turbante picudo, como su modelo, sostiene el ciborio que contiene su ofrenda de mirrra «como a Hombre». El séquito se ha eliminado por las evidentes faltas de espacio y las dificultades técnicas para introducir más figuras en la escena que, por lo demás, se atiene estrictamente al Evangelio y al modelo citado, aunque sea evidente la mayor tosquedad de la técnica, acentuada por la mala calidad de la piedra y el deterioro que ha sufrido.

En cuanto a las portadas de los brazos del transepto, la estructura arquitectónica de ambas es idéntica. Las dos están encuadradas por columnas de orden compuesto rematadas por jarrones; los vanos se abren entre pilastras jónicas; sobre los dinteles respectivos aparece tallado el escudo del mecenas Cardenal Arias. Los encasamientos con las escenas respectivas están flanqueados por nichos, a semejanza de los áticos en los retablos del siglo anterior. Están rematados por un frontón triangular el cual a su vez se encastra en otro curvilíneo que sustenta las respectivas figuras de sibilas. El Orbe y la Cruz, escudo del Cabildo Colegial, corona el conjunto.

La escena de la Encarnación o Anunciación de Jesús (Lucas 1, 26-38) (fig. 6) se desarrolla en el interior de la casa de María en Nazaret; la ubicación escénica viene determinada por un teatral cortinaje bajo el cual se sitúa un reclinatorio sobre el cual Ella está arrodillada, en posición frontal al espectador; este mueble está ornamentado con una gruesa guirnalda de flores y frutas de inspiración retabilística. María, al ser sorprendida por Gabriel, abre las ma-

25 En el momento del parto de María, José fue a buscar dos comadronas; una de ellas, Zelomi, la tocó y creyó inmediatamente en su triple virginidad; la otra, Salomé, no lo creyó y como castigo su mano quedó paralizada, aunque se curó al tocar al Recién Nacido (Los Evangelios Apócrifos. Traducción, introducción y notas de Edmundo González-Blanco. 3 Vol. Madrid, 1934; Vol. I, Cap. XIII, 1-7: pp. 378-379). 
nos y gira su rostro hacia el visitante, dando a su cuerpo una torsión «serpentinata». Esta figura presenta un trabajo en altorrelieve, mientras que Gabriel ha sido realizado en bulto redondo el cual, siguiendo la normativa de Francisco Pacheco, se sitúa arrodillado ante ella, pronunciando su salutación. En el frontón aparece representado el Padre Eterno, y a modo de rompimiento de gloria, le acompaña un ángel-niño. Flanquean la escena, de sus correspondientes hornacinas Santo Domingo de Guzmán y San Antonio, el primero como fundador de la Orden de Predicadores, la primera en instalarse en nuestra ciudad tras la Reconquista y el segundo como figura de gran devoción entre los Franciscanos, quienes también llegaron a Jerez tras pasar la ciudad a manos cristianas.

En cuanto a las figuras de las Sibilas, en este caso una de ellas presenta en una mano unas hojas de laurel, planta considerada atributo de Apolo y, por lo tanto, como propiciatoria para la adivinación del porvenir; la otra porta un caduceo, atributo de Mecurio también relacionado con las artes mánticas.

En la escena de la Visitación (fig. 7) (Lucas 1, 39-45) se representa a María e Isabel durante la escena del encuentro entre ambas en la cual Isabel pronuncia las palabras «iBendita tú entre las mujeres y bendito el fruto de tu vientre!».

Las figuras, en posición de tres cuartos, están realizadas en bulto exento con excelente técnica, sobrios movimientos y elegantes posturas; la Virgen muestra un peinado recogido detrás, formando bandas sobre las orejas, muy similar al de las Sibilas de la puerta central; su manto es envolvente, similar en su grueso plegado a los descritos en la mencionada portada. Isabel cubre su cabeza con un fino velo que forma delicados pliegues sobre el delantero de su túnica. Los brazos, en parte desaparecidos, acompañan rítmicamente los gestos de rostros y labios, ilustrando comedidamente la salutación. Para Bossuet simbolizaba el abrazo entre la Iglesia y la Sinagoga.

San José y Zacarías flanquean este relieve sin formar parte de la escena; son dos figuras también de bulto redondo muy bien ejecutadas técnicamente. San José (fig. 8) está situado en el lado de la Virgen, es un hombre de mediana edad, barba corta y cabello largo cuya movida túnica con plegado en tridente y el manto que descansa sobre su brazo izquierdo recuerda a Arce.

Zacarías, de mayor edad, barba larga y bífida y túnica, asimismo de pliegues muy movidos, guarda gran semejanza con la imagen de San José que se conserva en la puerta del mismo nombre de la parroquia de San Miguel y que también podemos relacionar con este escultor. 

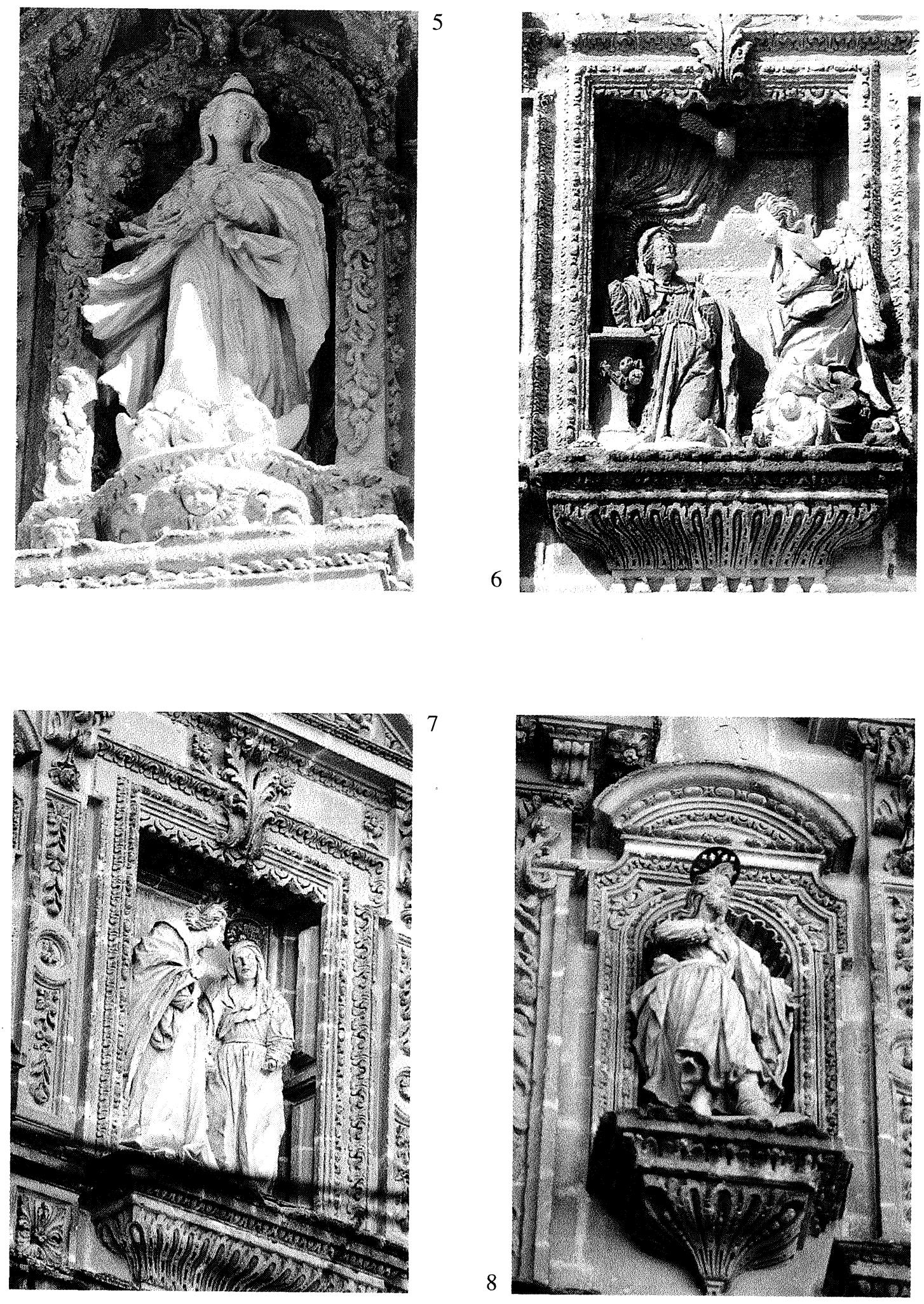

Figura 5. José de Mendoza. Inmaculada, en Portada Principal.

Figuras 6-8. José de Mendoza, atrib. La Anunciación, Puerta de la Epístola. La Visitación, Puerta del Evangelio, San José, Puerta del Evangelio. Jerez de la Frontera (Cádiz). Catedral. 


\section{Apéndice documental}

Archivo Histórico Diocesano de Jerez de la Frontera.

Catedral. Cuentas de la Obra del Nuevo Templo, 1738-1741. Caja 6.

Tengo ajustado con Joseph de Mendoza que ha de hacer las efigies para la Puerta Mayor a 15 Pesos de a 8 de Ptas. cada una y para las dos puertas de los lados los dos Misterios de Nacimiento y Epifanía a 45 Pesos cada una / Por cuenta le di 5 Pesos dia 19 de Marzo de 1737 año 075 (siguen distintos pagos inespecíficos): / En 17 de Junio por una piedra Mara que llevó se le ponen 26 Reales Vellón 26. / En 27 Junio por 14 Tablas a 1/2 Peso cada una 105. / En 12 de Septiembre le dio Cantero 5 Pesos 075. / En 13 de septiembre le di 18 Reales Vellon con cuya cantidad está pagado de las nuevas efigies hasta San Rafael 018. / En 17 de Septiembre le envié con el Aprendiz 2 Pesos 030. / En 12 de octubre le di 6 pesos con que acabe de pagar el San Gabriel que acabo en dicho dia 090. / En 7 de Noviembre de 737 años llevó Mendoza 10 Tablas a precio de 7 Reales y 1/2 cada una. Valen 75 R. 075. / En 11 de Noviembre de 737 años llevó 30 Reales que le dio cantero 030. / En 23 de Noviembre de 737 años pagué 75 Reales Vellón con que se le pagó la efigie de S. Pedro en el Misterio del Tabor 075. / En 2 de Diciembre llevó 135 Reales a cuenta de otra efigie 135. / En 24 de Enero de 38 años le di 20 pesos para ¿enseres? 300. / En 8 de Febrero le di 10 Reales Vellón para Maestro de Cantero 010. / En 15 de Febrero le di 20 Pesos en oro 300. / Tiene hecho hasta dicho dia 15 llameros a 4 Reales Vellón y 2 tulipanes.

En 11 de Marzo de 38 años le ajusté la cuenta a Mendoza y con 166 Reales Vellón que le di tiene pagados 17 efigies que tiene hechas y más le pagué 18 llameros a 4 Reales Vellón cada uno y 4 tulipanes que talló a 15 Reales Vellón cada uno 3.957. Pasado. / En 14 de Agosto le di 7 Pesos con que le acabé de pagar dos efigies y tres tulipanes. Más le di 1 Peso por un tulipán en 16 de agosto 015. / Pasado. / En 4 de Mayo de 39 años ajusté cuentas con Mendoza y con 6 Pesos que le di va pagado de todas las 22 efigies que tiene hechas hasta dicho día. / Tuvieron de costa las 22 efigies que se hicieron a 15 Pesos cada una: 4.920 Reales V. 4.920. / En 4 de Mayo de 39 años ajusté cuentas con Mendoza y con 6 Pesos que le di va pagado de todas las 22 efigies que tiene hechas hasta dicho día. / Tuvieron de costa las 22 efigies que se hicieron de Martelilla para la Puerta Mayor a 15 Pesos cada una: 4.920 Reales V. 4.920.

En 16 de Julio de 39 años le di a Joseph de Mendoza 518 Reales Vellón que importó la talla que hizo en la Puerta Mayor de algunos Ángeles que fueron por un tanto que todo importa la dicha cantidad 518. Abonado. / En 20 de Agosto de 41 años ajusté con Joseph de Mendoza los florones de los remates a 4 Reales y 1/2 de Vellón cada uno y por cuenta le di 20 Reales Vellón día 27 de Agosto 020. / En 16 de Septiembre le di 20 Reales Vellón con que le pagué 30 remates a 4 Reales Vellón. / Más le pagué los Ángeles que hizo en las monteras de los caracoles con 12 Pesos 180 . Pasado.

Cuenta de el Pintor que es Diego de Mendoza. / En 12 de Junio de 39 años le di 25 Pesos por cuenta de la pintura de los Santos 375. / En 9 de Julio se le dieron 822 Reales Vellón con que se le acabó de pagar 822. / En 27 de Julio di por orden de el Sr. D. Francisco Gutiérrez 24 Pesos de a 8 de plata para el pintor 360. / En 27 de Julio volvió el Sr. Gutiérrez por esta cuenta 472 Reales Vellón que se pusieron en la Caja 472. / Abonados 4.085 Reales.

Cuenta de latonero que es Vicente Sabariego. / En 15 de Abril de 37 pague a Vicente Sabariego 24 libras y $1 / 2$ de metal a 6 Rs. Vn. la libra que pesaron las dos diademas, una espada las dos llaves y cuatro garras. Todo es 147 Rs. Vn. 147. / Y siguen otros pagos por coronas, sol, bastón y otros aditamentos de las imágenes. 